\title{
Mechanism of Precipitation Increase with Urbanization in Tokyo as Revealed by Ensemble Climate Simulations
}

\author{
HIROYUKI KUSAKA \\ Center for Computational Sciences, University of Tsukuba, Tsukuba, Ibaraki, Japan \\ Keiko NAwATA* AND Asuka SUZUKi-PARKer \\ Graduate School of Life and Environmental Sciences, University of Tsukuba, Tsukuba, Ibaraki, Japan \\ YUYA TAKANE \\ Research Institute for Environmental Management Technology, National Institute of Advanced Industrial \\ Science and Technology, Tsukuba, Ibaraki, Japan \\ NANA FURUHASHI ${ }^{+}$ \\ Graduate School of Life and Environmental Sciences, University of Tsukuba, Tsukuba, Ibaraki, Japan
}

(Manuscript received 5 February 2013, in final form 27 November 2013)

\begin{abstract}
This study examines how urbanization affects the precipitation climatology in Tokyo, Japan. A unique aspect of this study is that an ensemble, regional climatological simulation approach is used with sensitivity experiments to reduce uncertainty arising from nonlinearity in the precipitation simulations. Another aspect is that the robustness of the precipitation response is tested with "stress response" simulations with increasing urban forcing. The results show that urbanization causes a robust increase in the amount of precipitation in the Tokyo metropolitan area and a reduction in the inland areas. These anomalies are statistically significant at the $95 \%$ and $99 \%$ levels in some parts. There is no measureable change in the surrounding rural and ocean areas. These precipitation responses are attributed to an increase of surface sensible heat flux in Tokyo, which destabilizes the atmosphere and induces an anomalous surface low pressure pattern and the convergence of grid-scale horizontal moisture flux. The anomalous convergence of grid-scale horizontal moisture flux is a consequence of urbanization modifying the sea breeze.
\end{abstract}

\section{Introduction}

Urbanization alters the amount, intensities, and spatial patterns of precipitation in and around urban areas in a large plain. An extensive historical field campaign project, the Metropolitan Meteorological Experiment (METROMEX), showed that the urban heat island (UHI) increased the frequency and the amount of

* Current affiliation: Taiho Pharmaceutical Co., Ltd., Tokyo, Japan.

${ }^{+}$Current affiliation: Japan Weather Association, Tokyo, Japan.

Corresponding author address: Hiroyuki Kusaka, Center for Computational Sciences, University of Tsukuba, 1-1-1 Tennodai, Tsukuba, Ibaraki 305-8572, Japan.

E-mail:kusaka@ccs.tsukuba.ac.jp summertime precipitation in and downwind of St. Louis, Missouri (Huff and Changnon 1972; Changnon 1981). Later observational studies supported the METROMEX results (Westcott 1995; Orville et al. 2001; Shepherd et al. 2002; Dixon and Mote 2003; Burian and Shephard 2005; Mote et al. 2007; Niyogi et al. 2011). Tokyo, Japan, the world's largest metropolitan area, is no exception. There is evidence that central Tokyo had an increasing precipitation trend that is higher than the surrounding areas during the warm season (Fujibe et al. 2009). However, Fujibe et al. (2009) describe the above investigation of urban impact on precipitation by observational study as limited. Also, the mechanism driving urban impact on precipitation in Tokyo is not well understood as compared with cities in the United States. Numerical studies are expected to help us better understand the urban influence of Tokyo. 
Numerical models have been used to examine the sensitivity of precipitation to urbanization. Using a two-dimensional mesoscale model, Thielen et al. (2000) and Baik et al. (2001) showed that urbanization produces convective precipitation over and downwind of urban areas under idealized, favorable atmospheric and geographic conditions. Rozoff et al. (2003) conducted a realistic simulation of a convective precipitation event in St. Louis using a three-dimensional mesoscale model, and the results showed that urban thermals affect convective initiation and increase precipitation downwind of the St. Louis urban area. Later numerical studies supported their results for other cities: Houston, Texas (Burian and Shephard 2005; Shem and Shepherd 2009); Sydney, Australia (Gero and Pitman 2006); and Taipei, Taiwan (Lin et al. 2011).

Several numerical studies have been conducted for Tokyo as well, but there remains considerable uncertainty as to what degree and how urbanization impacts the precipitation behavior. Matheson and Ashie (2008), for example, conducted sensitivity experiments for two summertime convective rainfall events in Tokyo, and obtained mixed results; the urban area increased precipitation for one rainfall event, but decreased it for the other. They suggested that this difference in precipitation response had a physical significance. However, convective rainfall responds nonlinearly to initial conditions and model configurations. Thus, simulated results based on a single or a few cases, such as in the Matheson and Ashie study, can leave considerable uncertainty. This is especially true for locations such as Tokyo where influences from a nearby ocean and mountains may easily outweigh the urban effects on precipitation. Numerical simulation results from Beijing, China (e.g., Miao et al. 2011; Guo et al. 2006; Zhang et al. 2009), have also yielded mixed results regarding urban impacts on precipitation. Their simulated urban impacts often exhibit spatially nonsystematic patterns, which may be as a result of the complex terrain around Beijing, and/or the scale of the urban extent of Beijing (Miao et al. 2011).

In 2009, our group ran a case study on the uncertainties of the urban effect (Kusaka et al. 2009). We found that small changes to the physics scheme can change the sign of the precipitation response; moreover, the choice of the initial and lateral boundary conditions could also change the sign of the response. Such an uncertainty arises from nonlinearities in the model. To reduce the uncertainty, Kusaka et al. (2009) proposed doing sensitivity experiments based on ensemble or climate simulations. Shimoju et al. (2010) and Inamura et al. (2011) adopted the ensemble simulation approach and attempted to examine the urban influence on several rainfall events. However,
TABLE 1. Model configuration. Here, ARW indicates the Advanced Research configuration of WRF.

\begin{tabular}{ll}
\hline \hline Model & ARW-WRF, version 3.0.1.1 \\
Shortwave radiation & Dudhia \\
Longwave radiation & RRTM \\
Cloud microphysics & WSM6 \\
Planetary boundary layer & YSU \\
Land surface & Noah LSM coupled with the \\
& single-layer UCM \\
Simulation period & 0000 UTC 27 Jul-0000 UTC \\
& 1 Sep 2001-08 \\
Horizontal grid spacing & $4 \mathrm{~km}$ \\
Total No. of vertical layers & 35 \\
\hline
\end{tabular}

the simulated precipitation pattern did not agree well with the observations. In addition, the spatial pattern of the urban impact on precipitation was spatially disorganized, which means uncertainty remained even with the ensemble simulation approach in the case study.

A potential shortfall of the work of Shimoju et al. (2010) and Inamura et al. (2011) was that the ensemble simulations were conducted for particular precipitating events with an insufficient number of ensemble members. However, with the climatological ensemble simulation approach, it is expected that the urban impact will stand out against nonlinear precipitation responses and the uncertainty will be reduced. The key ideas here are the treatment of the problem as a boundary-value problem instead of an initial-value problem and the increasing number of precipitation events to be simulated. Therefore, this study aims to examine how urbanization affects precipitation in Tokyo by the ensemble climate simulation approach. Furthermore, a series of sensitivity experiments with four urban scenarios are conducted in order to examine the robustness of the urban influence on precipitation climatology.

\section{Experimental design}

We use the Weather Research and Forecasting (WRF) model, version 3.0.1.1 (Skamarock et al. 2008), to simulate the summertime precipitation over the Tokyo metropolitan area (hereinafter Tokyo). Model configurations are summarized in Table 1 . The model domain covers central Japan, including Tokyo (Fig. 1). The model domain is divided into grid elements of $120 \times 120$, which means a horizontal grid spacing of $4 \mathrm{~km}$. The model top is set to be $50 \mathrm{hPa}$, with 35 vertical $\sigma$ levels.

Concerning the physics schemes, for shortwave radiation, we used the Dudhia scheme, a simple model that efficiently treats clouds and clear-sky absorption and scattering (Dudhia 1989). For longwave radiation, we used the Rapid Radiative Transfer Model (RRTM), a model that accounts for multiple bands, trace gases, 

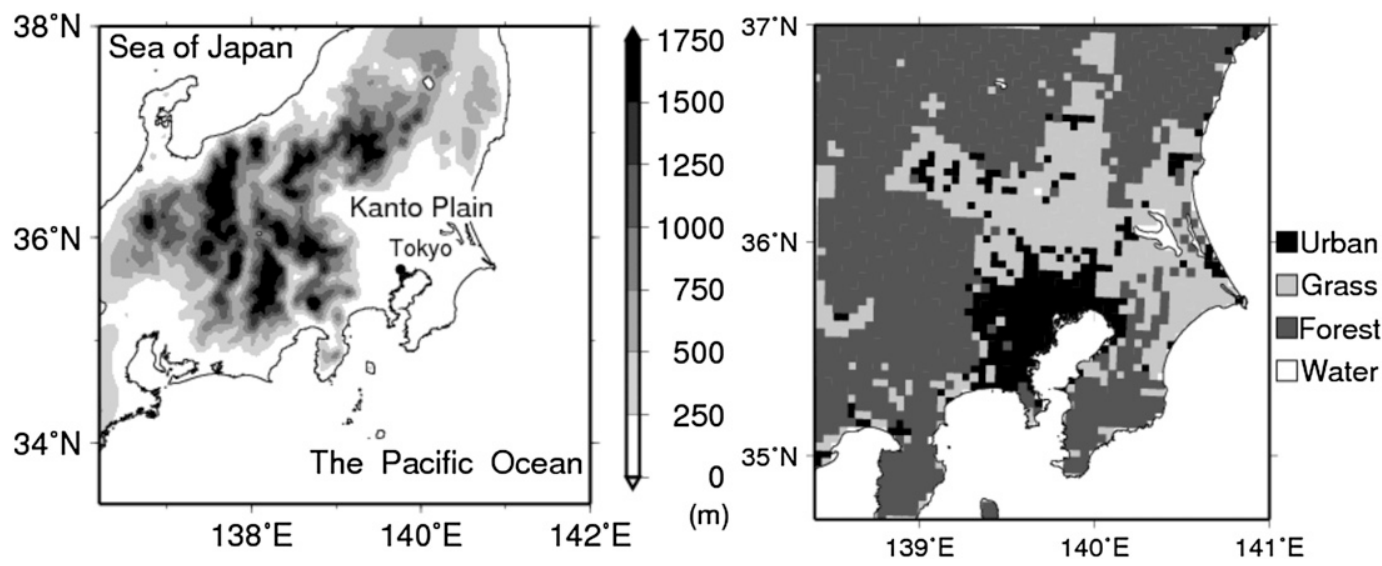

FIG. 1. Topography and land use of the model domain. (left) Topography of the 4-km WRF model domain. Grayscale indicates terrain height $(\mathrm{m})$. The solid circle marks Tokyo. (right) Land use of the Tokyo metropolitan area and its surroundings. Black, dark gray, light gray, and white identify urban, forest, grass, and water surfaces, respectively. The large black area is the Tokyo metropolitan area.

and microphysics species (Mlawer et al. 1997). For microphysics, we used the WRF single-moment six-class (WSM6) microphysics scheme, a cold-rain model with water vapor, cloud, rain, ice, snow, and graupel processes (Hong et al. 2004). For the boundary layer turbulence, we used the Yonsei University (YSU) planetary boundary layer scheme, a nonlocal turbulent diffusion scheme with an explicit entrainment layer and parabolic diffusion coefficient profile in an unstable mixed layer (Hong and Pan 1996; Hong et al. 2006). For surface fluxes, we used the coupled scheme of the Noah land surface model (LSM; Chen and Dudhia 2001) and a singlelayer urban canopy model (UCM; Kusaka et al. 2001; Kusaka and Kimura 2004a,b).

The WRF model with the Noah-UCM coupled scheme has proven successful in simulating regional climatology as well as urban heat island phenomena (e.g., Chen et al. 2011; Kusaka et al. 2012a,b). This is because the singlelayer UCM represents the surface heat budget over the urban areas more accurately by considering the urban geometry and anthropogenic heat release (e.g., Kusaka et al. 2001; Kusaka and Kimura 2004a; Kusaka et al. 2012a). For instance, the UCM includes street canyons that are parameterized to represent the urban geometry, as well as a multilayer heat equation for rooftops, walls, and road interior temperatures, and it also calculates the surface temperatures of, and the heat fluxes from, the rooftops, walls, and roads (Fig. 2). In the UCM, the anthropogenic heat is released to the urban canopy layer as a sensible heat. Readers are referred to Kusaka et al. (2001), Kusaka and Kimura (2004a), and Chen et al. (2011) for more details of the UCM.

Four urban scenarios are considered here: a control (CTRL) scenario, which has urban surface parameters such as building height and anthropogenic heat values taken as average values from the present-day Tokyo; a high-building (HB1) scenario, which has higher buildings and greater anthropogenic heat than CTRL; a highbuilding, double anthropogenic (HB2) scenario; and a no-urban (NU) scenario in which Tokyo's urban area is replaced by grassland (Table 2). Urban parameter values for each of the scenarios are listed in Table 3 . The parameters in CTRL roughly correspond to the building height and anthropogenic heat release of the residential areas because commercial and high-profile residential buildings cover only a few spots in the metropolitan area.

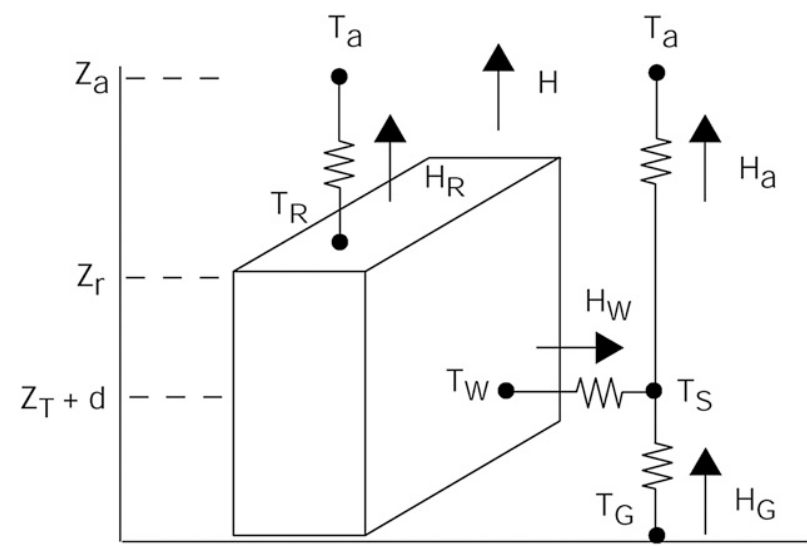

FIG. 2. Temperatures and heat fluxes in the single-layer UCM: $T_{a}$ is the air temperature at reference height $Z_{a}, T_{R}$ is the building roof temperature, $T_{W}$ is the building wall temperature, $T_{G}$ is the road temperature, and $T_{S}$ is the temperature at height $Z_{T}+d$. In addition, $H$ is the sensible heat exchange at the reference height, $H_{a}$ is the sensible heat flux from the building canyon to the atmosphere, $H_{W}$ is that from wall to canyon space, $H_{G}$ is that from road to canyon space, and $H_{R}$ is that from roof to atmosphere. 
TABLE 2. Summary of urban scenarios.

\begin{tabular}{cc}
\hline \hline Urban scenario & \multicolumn{1}{c}{ Description } \\
\hline CTRL & $\begin{array}{c}\text { Low residential building profile; Tokyo } \\
\text { metropolitan area average } \\
\text { High residential and commercial building } \\
\text { profile; central Tokyo average } \\
\text { HB1 }\end{array}$ \\
As in HB1, but with doubled anthropogenic \\
heat release \\
NU
\end{tabular}

Instead of simulating specific rainfall events, which can be misleading due to the high nonlinearities present, we simulate the precipitation climatology. Design of the numerical time integration follows the previous study by Kusaka et al. (2012a,b). The time integration covers from 27 July to 1 September for the years 2001-08, referred to here as eight consecutive Augusts in the timeslice experiment approach, which means that there is a single simulation for each month. The first 4 days of each simulation are the model spinup, and thus their results are discarded. Using the terminology of Castro et al. (2005), the present simulation is a type-2 dynamical downscaling in which the results are independent of the initial atmospheric conditions, yet dependent on the lateral and bottom boundary conditions.

Regional climate simulation is affected by boundary conditions. Also, eight years may still be insufficient to draw conclusions about the urban impact on precipitation at climate scale. An ensemble experiment is one of the appropriate solutions to reduce the uncertainty associated with the above problems. Consequently, this study uses the ensemble experiment approach using multiple initial and boundary conditions (Fig. 3). Ensemble members are generated using four objective analysis datasets as initial and lateral boundary conditions. With eight consecutive Augusts, and four initial and boundary conditions, the method provides a virtual realization of 32 years of Augusts. The four objective analysis datasets are 1) mesoscale analysis data with a 10-km horizontal grid increment created by the Japan Meteorological Agency (JMA-MANAL), 2) regional analysis data with a $20-\mathrm{km}$ horizontal grid increment created by the JMA (JMA-RANAL), 3) Japanese reanalysis data with a $1.25^{\circ}$ grid increment created by the JMA and the Central Research Institute for Electric Power Industry (JMA/CRIEPI-JRA25), and 4) final analysis data with a $1.0^{\circ}$ grid increment created by the National Centers for Environmental Prediction (NCEPFNL). The last two ensemble members have a $20-\mathrm{km}$ horizontal grid spacing in the outer domain to solve the boundary-gap problem. The land surface data are
TABLE 3. Parameters used in the single-layer UCM. The value in parentheses is the gross building coverage ratio.

\begin{tabular}{llcc}
\hline \hline & CTRL & HB1 & HB2 \\
\hline Green fraction & 0.3 & 0.1 & 0.1 \\
Building height $(\mathrm{m})$ & 9.0 & 16.0 & 16.0 \\
Building coverage & 0.35 & 0.35 & 0.35 \\
$\quad$ ratio & $(0.245)$ & $(0.245)$ & $(0.245)$ \\
$\begin{array}{l}\text { Thermal inertia } \\
\quad\left(\mathrm{J}^{2} \mathrm{~s}^{-1} \mathrm{~K}^{-2} \mathrm{~m}^{-4}\right)\end{array}$ & $3.52 \times 10^{6}$ & $3.52 \times 10^{6}$ & $3.52 \times 10^{6}$ \\
$\begin{array}{l}\text { Area-averaged, daily } \\
\text { mean anthropogenic } \\
\text { heat }\left(\mathrm{W} \mathrm{m}^{-2}\right)\end{array}$ & & & \\
$\quad$ & & 55.0 & 110.0 \\
\hline
\end{tabular}

provided by the National Land Numerical Information dataset from the Geospatial Information Authority of Japan.

\section{Results}

\section{a. Verification of control simulations}

For the CTRL case, we first compare the resulting precipitation climatology from the WRF model simulation with observations from the Automated Meteorological Data Acquisition System (AMeDAS) network operated by the JMA. The simulated spatial distribution of precipitation in August from the CTRL simulation averaged over four ensemble members agrees well with the observations (Fig. 4; results from individual ensemble members are also provided in Fig. A1 of the appendix). The WRF model reproduced the general features of the observed precipitation distribution, with a spatial correlation of 0.78 and an RMSE of $59.6 \mathrm{~mm}$. The model captures the geographical characteristics of the precipitation distribution in great detail: for example, by showing higher precipitation in the mountainous region compared to the plain region, with the plain region showing slightly higher precipitation in the northern and eastern parts.

All of the past numerical studies for Tokyo are based on case studies suffered from the inadequate reproducibility of the observed precipitation (e.g., Matheson and Ashie 2008; Shimoju et al. 2009, 2010; Inamura et al. 2011; Nakano et al. 2013). However, with an ensemble climate simulation approach, the current study was able to produce a good level of agreement between the simulated and observed precipitation patterns. In mathematical (or computational science) terms, this is associated with the treatment of the problem as a boundary-value problem instead of as an initial-value problem.

However, the model has a tendency to overestimate the overall precipitation amount, as indicated in the scatter diagram of the observed and simulated 
CTRL

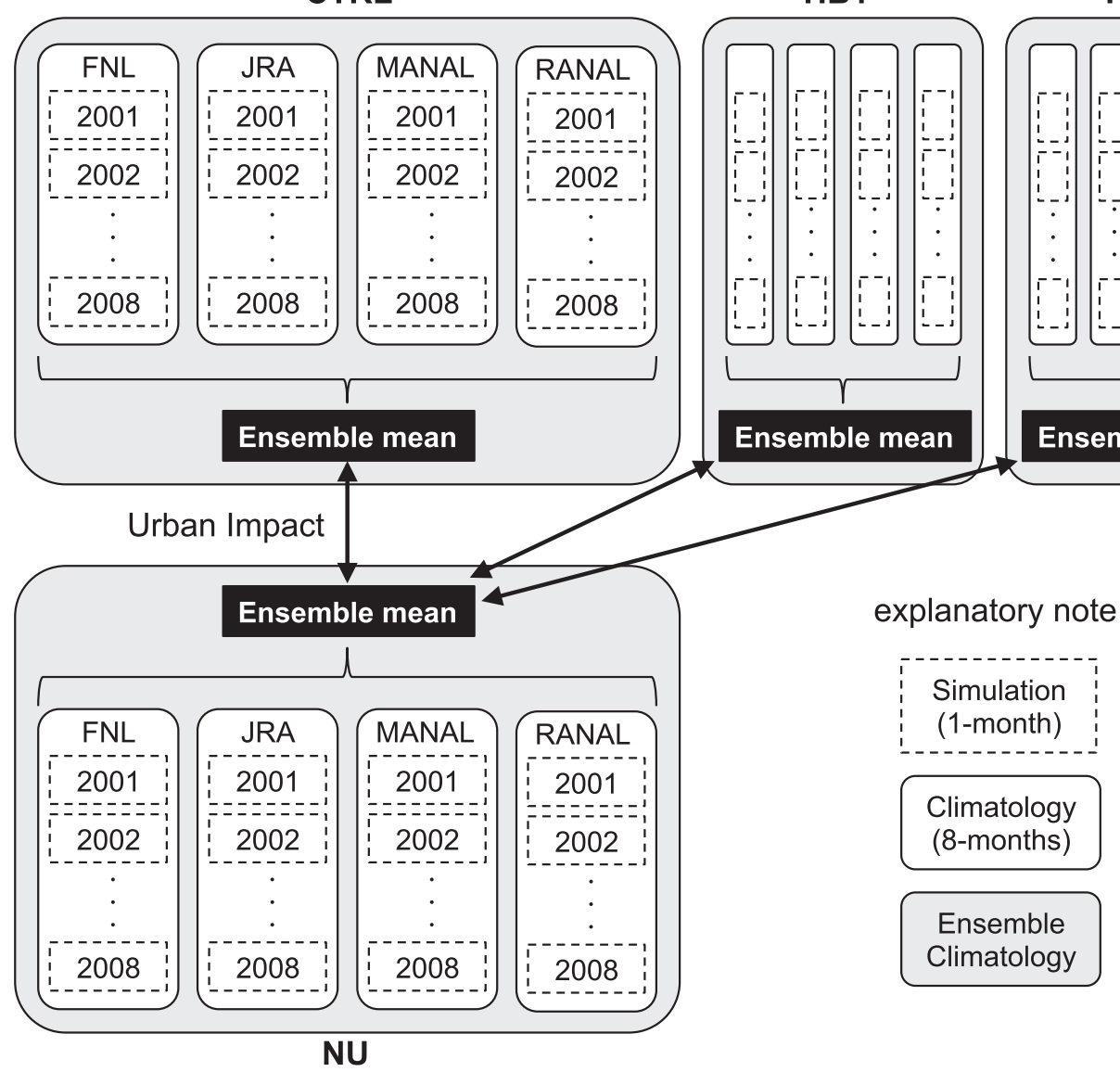

HB2

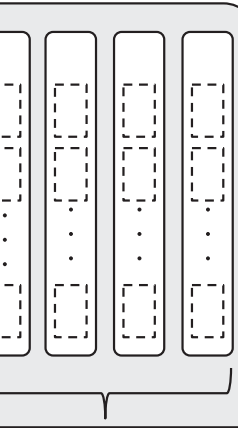

nsemble mean

FIG. 3. A schematic diagram of the ensemble simulation approach.

precipitation (Fig. 5). The bias is $+27.7 \mathrm{~mm}^{\text {month }}{ }^{-1}$, which is equivalent to a $+24 \%$ overestimation. The frequency distribution of precipitation is generally well simulated (Fig. 6). However, the frequency of light precipitation is slightly underestimated, whereas heavy precipitation is slightly overestimated. Precipitation biases are common to many regional climate models (e.g., Ishizaki et al. 2012; Kusaka et al. 2010), and bias reduction is an ongoing effort. It is reasonable to assume that these model biases exist in all urban scenario simulations; therefore, differences among the urban scenario simulations are independent of model biases.

\section{b. Urban impacts on precipitation climatology}

Comparing the CTRL and NU experiments provides an estimate of the urban impact on the precipitation of present-day Tokyo. Figure 7a shows the percent change for CTRL from NU in the ensemble mean monthly precipitation climatology for August. A positive anomaly of $10 \%-15 \%$ occurs in the coastal area of Tokyo, which is statistically significant at least at the $95 \%$ level, reaching $99 \%$ in some parts (Fig. 8a). Although surrounding areas have small patches of positive and negative anomalies, most have no statistical significance. Anomalies are mainly negative in the plain area to the north and in the foothills. Some of these negative anomalies are statistically significant, particularly in the foothills.

The robustness of the precipitation response from urbanization is further examined with our HB1 and HB2 experiments. Figure $7 \mathrm{~b}$ shows the percent change for HB1 from NU. Similar to the anomaly for CTRL, there is a positive anomaly in Tokyo but its magnitude increases to $15 \%-20 \%$. This is statistically significant, at the least, at a $95 \%$ level, and reaches the $99 \%$ level in some parts (Figs. $7 \mathrm{~b}$ and $8 \mathrm{~b}$ ). Moreover, the increased urbanization extends the area of the positive anomaly. This trend continues in HB2, with the magnitude exceeding $20 \%$, and the region of positive anomaly growing even broader (Fig. 7c). The area of statistically significant positive anomaly is also larger than that in CTRL and HB1 (Fig. 8c). Patchy anomalies north and east of central Tokyo remain in HB2, but areas with a statistically significant anomaly mostly disappear in the plain, except near the foothills. Here, it is noted that 

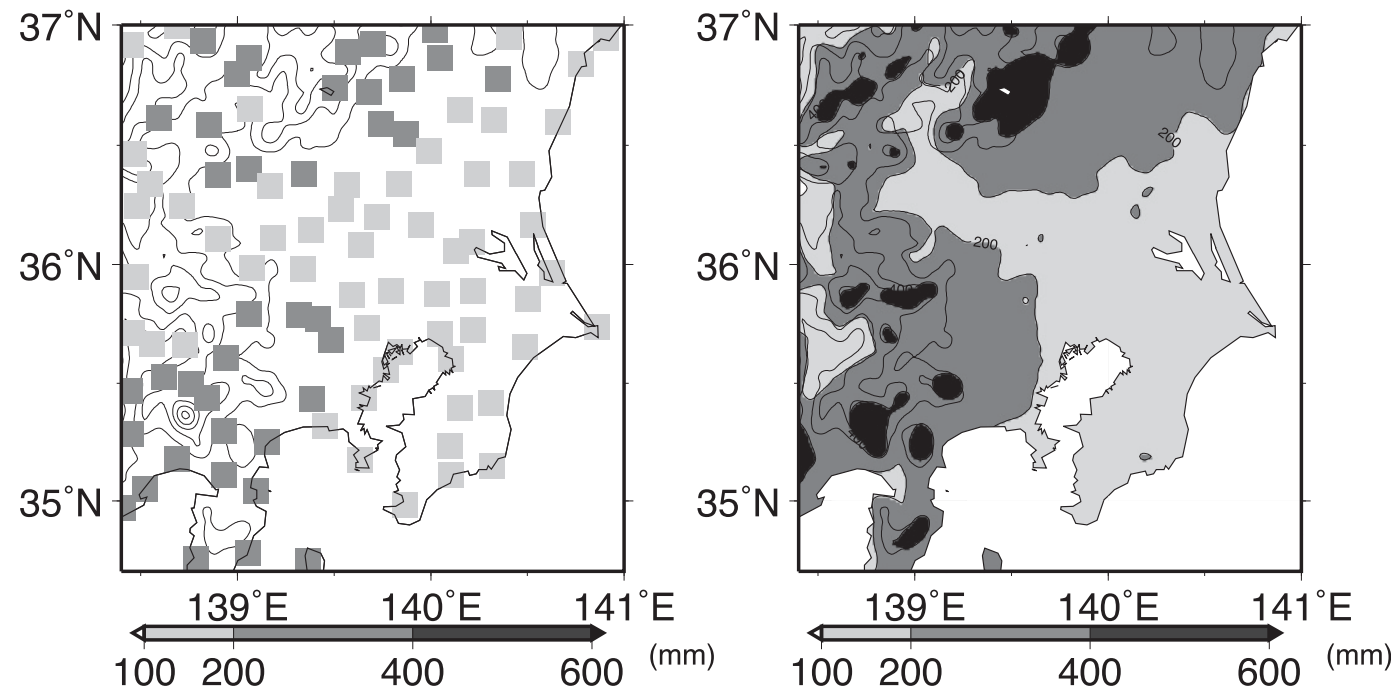

FIG. 4. Spatial distribution of monthly precipitation amount in August, averaged for the 8-yr period 2001-08. (left) AMeDAS observations and (right) ensemble mean from the CTRL simulation. Solid lines indicate terrain height.

uncertainty is suppressed in the present climatological simulations compared to earlier case studies.

These results show that greater urbanization increases the precipitation climatology in central Tokyo. Additionally, the results indicate a statistically significant precipitation response to urbanization. This means that the precipitation change signal from urbanization is outside the range of interannual variation and variations

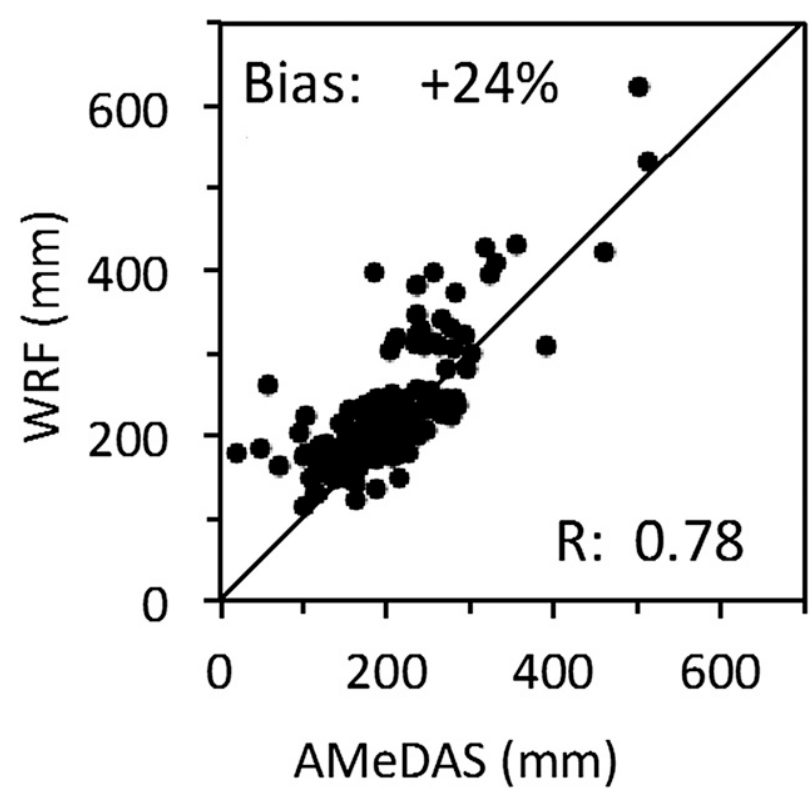

FIG. 5. Scatter diagram of the observed and CTRL monthly precipitation amounts in August averaged for 2001-08. The simulated value is an ensemble mean from the four WRF members. The correlation coefficient is indicated by $R$. in lateral boundary conditions (within the range of our four reanalysis datasets).

\section{c. Mechanism behind increased precipitation with urbanization}

Additional analyses are performed to understand the mechanisms behind the precipitation increase with urbanization.

A change in land use in the model modifies the surface fluxes at the lower boundary. This change modifies the PBL processes via the turbulent diffusion terms in the

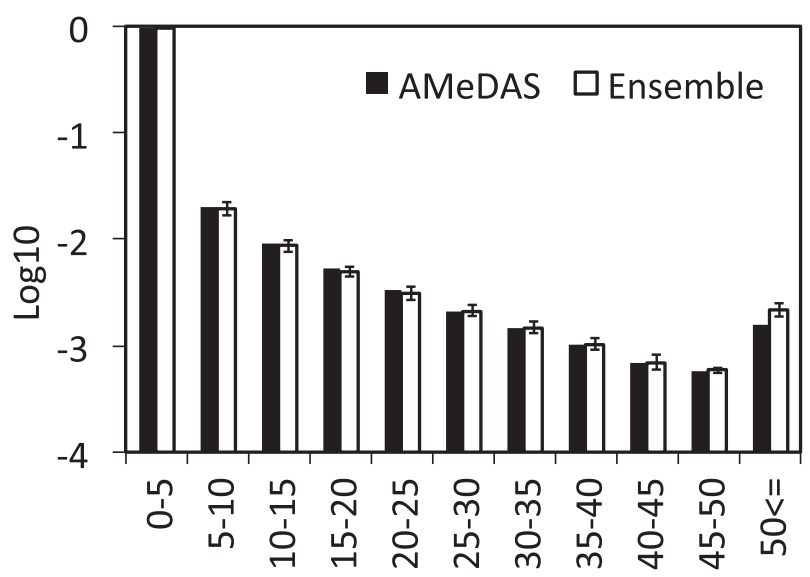

\section{Precipitation Intensity [mm/3hour]}

FIG. 6. Frequency of observed and simulated precipitation intensity per $3 \mathrm{~h}$ during $2001-08$. The frequency is normalized by the total number and shown on a logarithmic scale. 

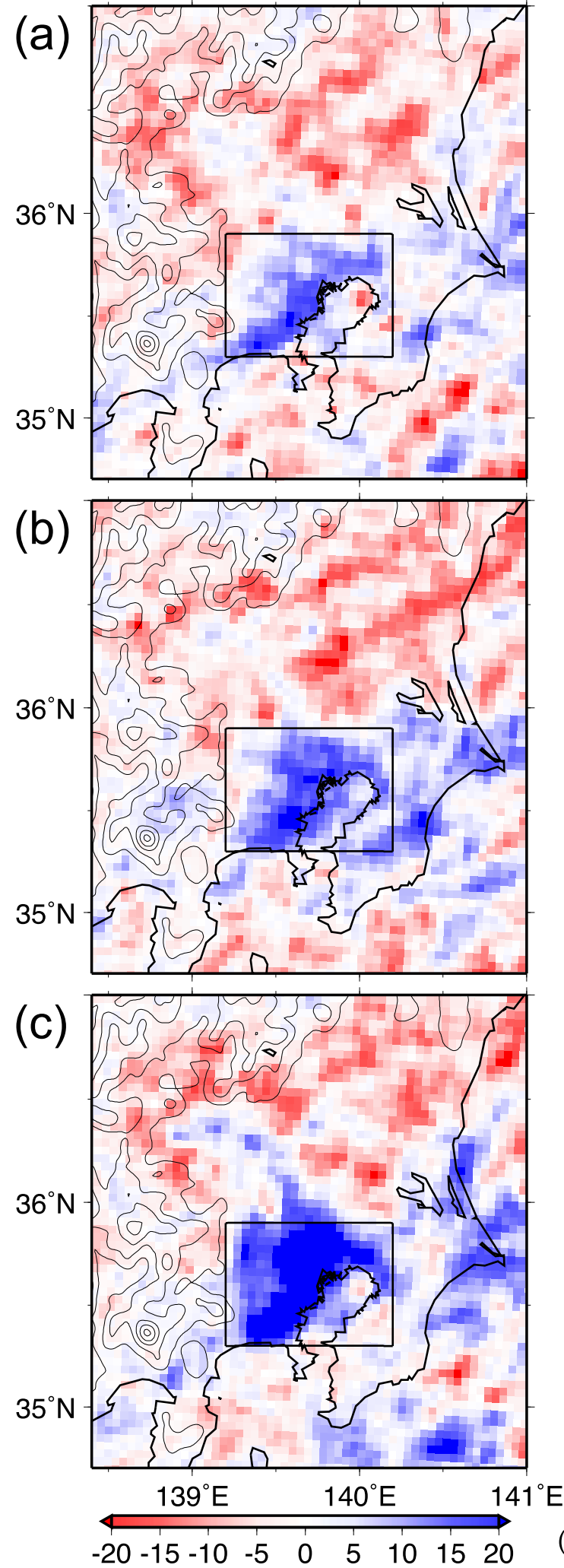

FIG. 7. Simulated urban impacts (anomalies from NU) on the monthly precipitation amount in August during 2001-08 for (a) CTRL, (b) HB1, and (c) HB2. Blue (red) indicates the increased (decreased) precipitation amounts from urbanization. All results are based on ensemble averages from each scenario.
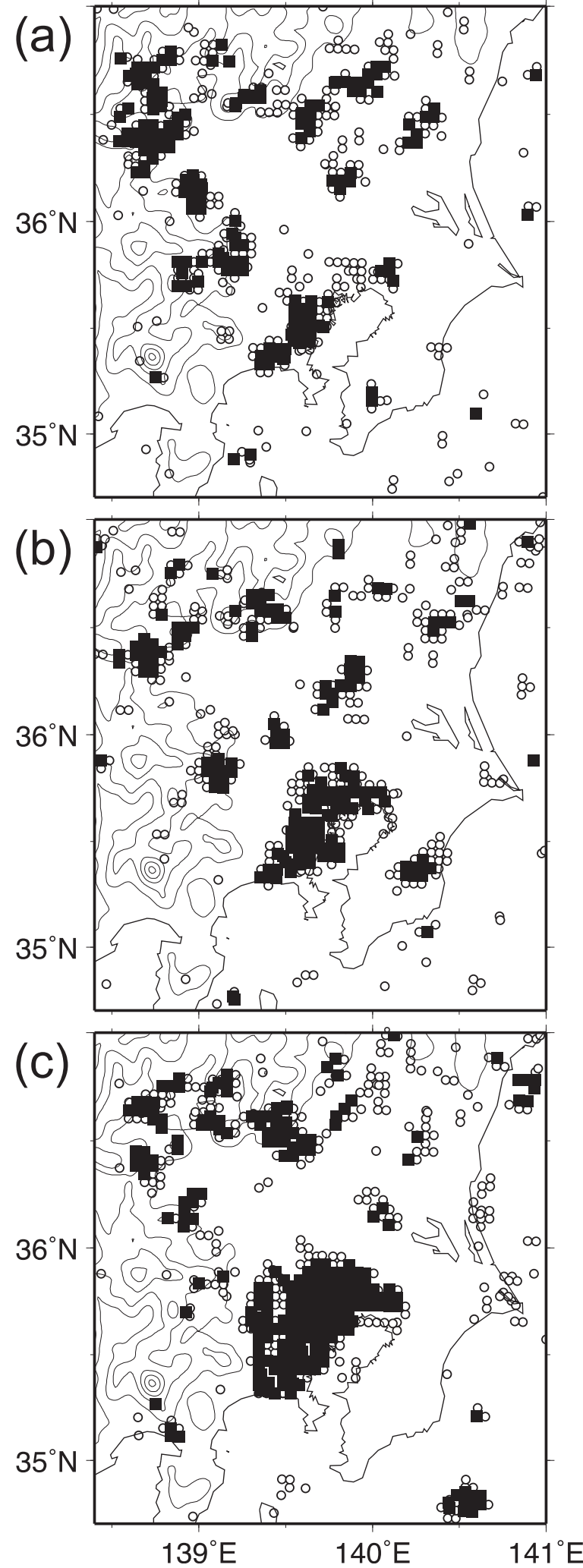

FIG. 8. Results of the Wilcoxon $t$ test of statistical significance for Fig. 7. Solid squares and open circles indicate significance levels of $99 \%$ and $95 \%$, respectively. 
(a)

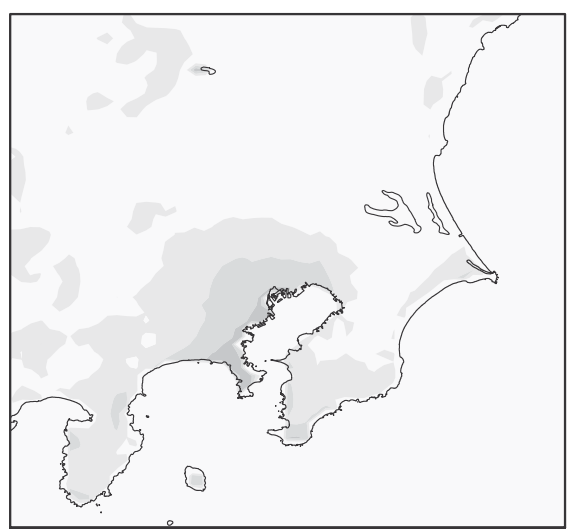

(c) (b)

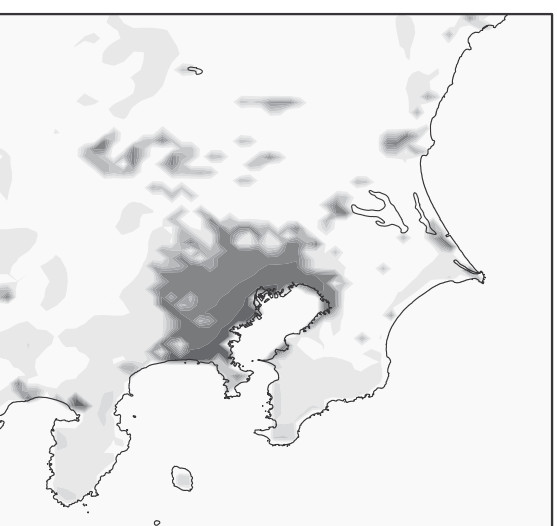

(d)

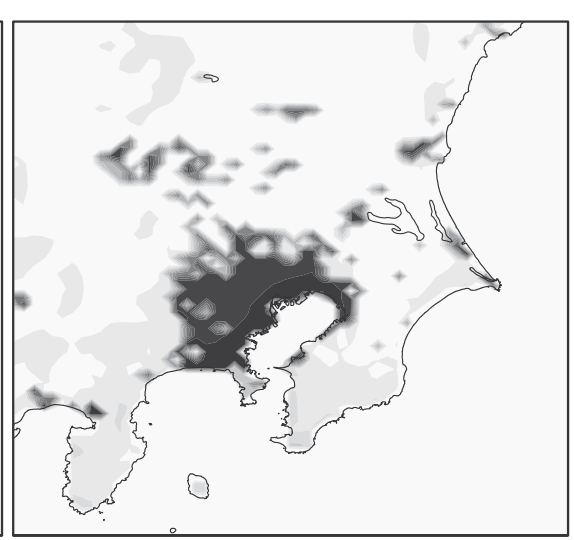

$\left[\mathrm{W} / \mathrm{m}^{2}\right]$
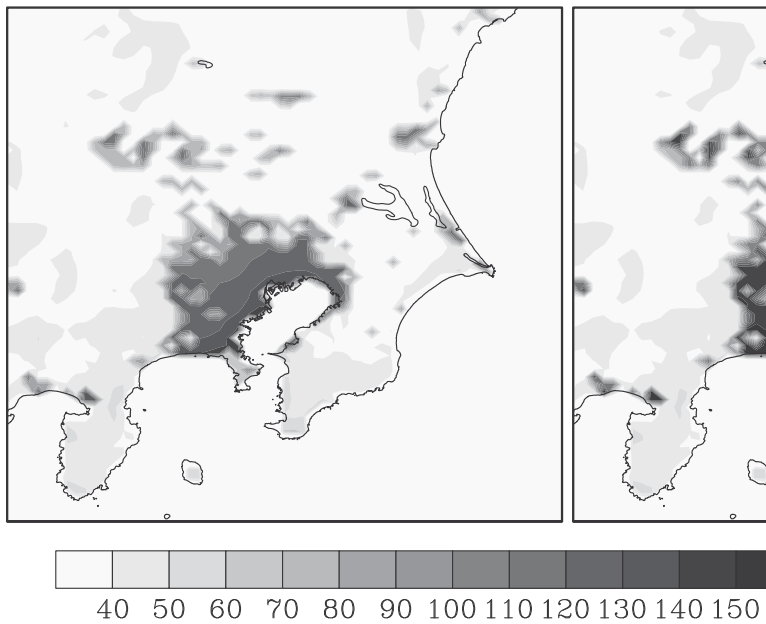

FIG. 9. Spatial distribution of ensemble mean monthly surface sensible heat flux $\left(\mathrm{W} \mathrm{m}^{-2}\right)$ during August averaged for 2001-08 for the (a) NU, (b) CTRL, (c) HB1, and (d) HB2 experiments.

momentum, heat, and moisture conservation equations. Changes in the PBL processes then propagate to the entire model atmosphere. Figure 9 shows the spatial distribution of the monthly surface sensible heat flux in August averaged for 2001-08 from the NU, CTRL, HB1, and HB2 simulations. In NU, the sensible heat flux is $20-70 \mathrm{~W} \mathrm{~m}^{-2}$ in the plain. The flux in the coastal areas is relatively larger compared to that in the inland areas. The larger flux is due to the relatively cold air and large wind speed of the sea breeze. In CTRL, there is little change in the inland area, but the sensible heat flux in the urban areas is increased to $90-130 \mathrm{~W} \mathrm{~m}^{-2}$, which is $60 \mathrm{~W} \mathrm{~m}^{-2}$ larger than in NU as a domain average. The sensible heat flux increase is even larger for the HB1 and HB2 cases ( 70 and $95 \mathrm{~W} \mathrm{~m}^{-2}$, respectively) relative to the NU case. Overall, the sensible heat flux change in the urban areas appears to be the dominant cause of the precipitation change.
Here, we consider the effects of the surface sensible heat flux increase on the atmosphere. The increase in the sensible heat flux over the urban areas raises the surface air temperature (Fig. A2 of the appendix), as well as the mean potential temperature and depth of the PBL. Indeed, the boundary layer heights in cases CTRL, HB1, and HB2 are higher by 150-200, 200-250, and $300-350 \mathrm{~m}$, respectively, relative to the CTRL case (Fig. 10). This elevated boundary layer height promotes atmospheric instability. As a climatological mean, the stability changes are small. However, even a slight decrease in stability may trigger precipitation when the background atmosphere is already slightly unstable. Moreover, further atmospheric instability can increase the precipitation intensity. Atmospheric destabilization associated with a sensible heat flux increase is likely a mechanism for the higher precipitation amounts in CTRL, HB1, and HB2. 
(a)

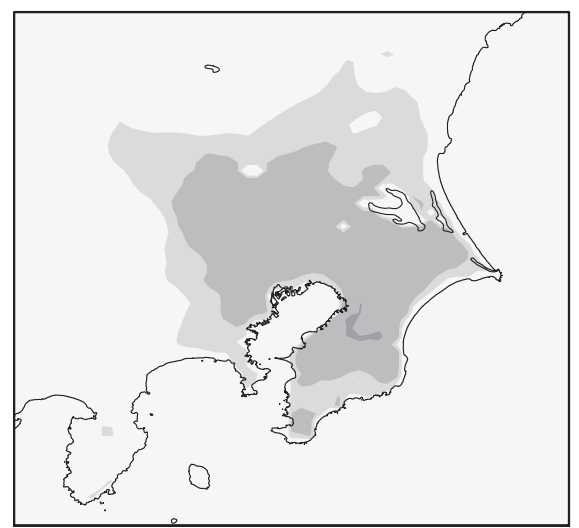

(c)

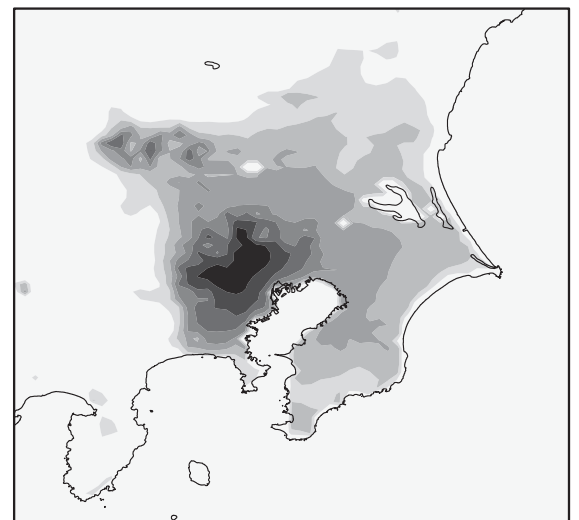

(b)

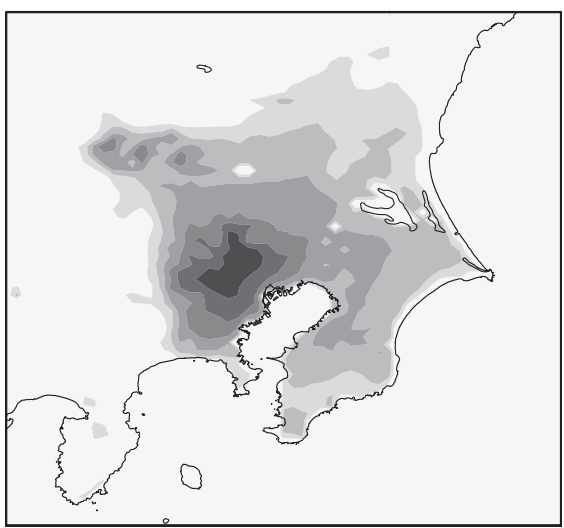

(d)
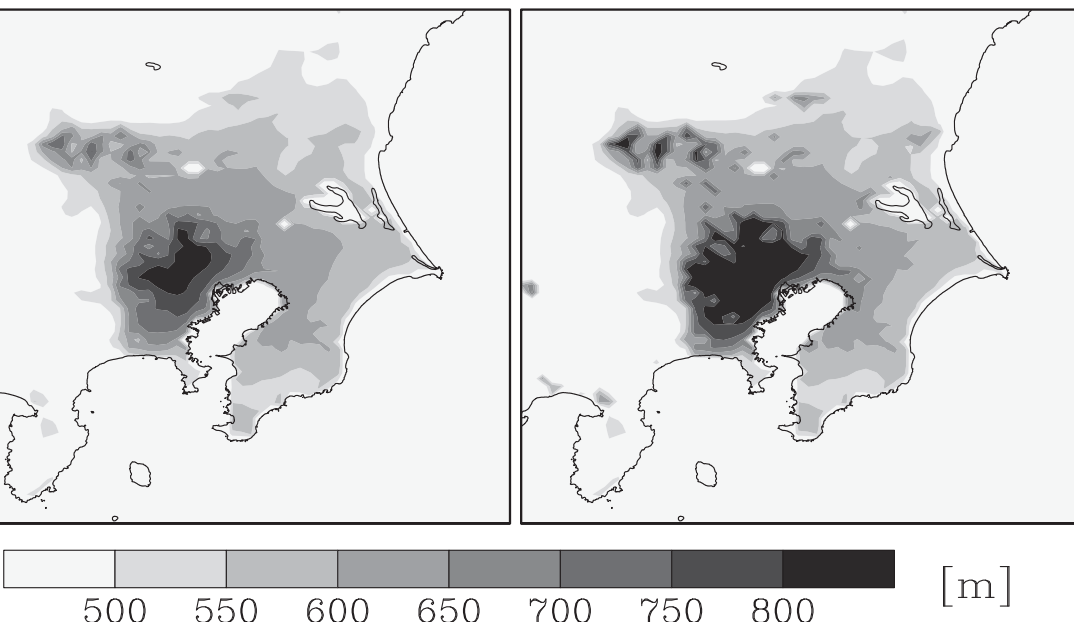

FIG. 10. As in Fig. 9, but for the PBL height (m).

The surface sensible heat flux increase also modifies the boundary layer structure, which produces an anomalous surface pressure depression (Fig. 11) and forms an anomalous convergence of horizontal winds. Figure 12 shows model grid-scale horizontal moisture flux at $200 \mathrm{~m}$ above the ground for CTRL. Here, southerly winds associated with the sea breeze dominate much of the analysis domain, producing a grid-scale horizontal moisture flux to central Tokyo and farther inland. However, with increased urban forcing, the anomalous surface low pressure in central Tokyo induces an anomalous gridscale horizontal moisture flux convergence (Fig. 12). From these figures, it is indicated that the metropolitan area enhances the moisture transport from the ocean and prevents transport to the inland area though modification of the sea breezes. It is considered that the reduction of precipitation in mountain regions is primarily due to this moisture flux change. In contrast, the latent heat flux from the urban surface decreases with urbanization. Despite this decrease, the precipitation amount increases in the metropolitan area. This indicates that the depletion of the latent heat flux is superseded by the anomalous horizontal moisture flux convergence.

To better understand the proposed mechanism, we consider the water budget in a column atmosphere over the metropolitan area:

$$
\frac{\partial \mathrm{PW}}{\partial t}=-\int_{z} \operatorname{div}\left(Q \mathbf{V}_{H}\right)+\int_{z} \operatorname{div}\left(-\overline{Q^{\prime} \mathbf{V}_{H}^{\prime}}\right)+Q_{E}-\mathrm{PR} .
$$

Here, PW is precipitable water, $Q$ is the total water content, and $\mathbf{V}_{H}$ is the horizontal wind vector. The lefthand side represents the temporal variation of precipitable water. The first term of the right-hand side is the vertically integrated divergence of the grid-scale horizontal $Q$ flux. The second term is the vertically 
(a)

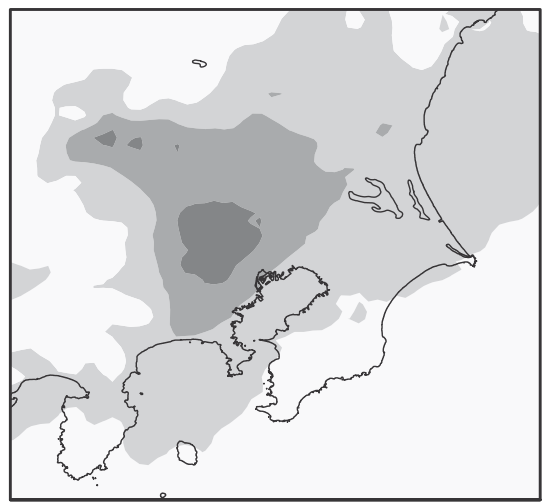

(b)

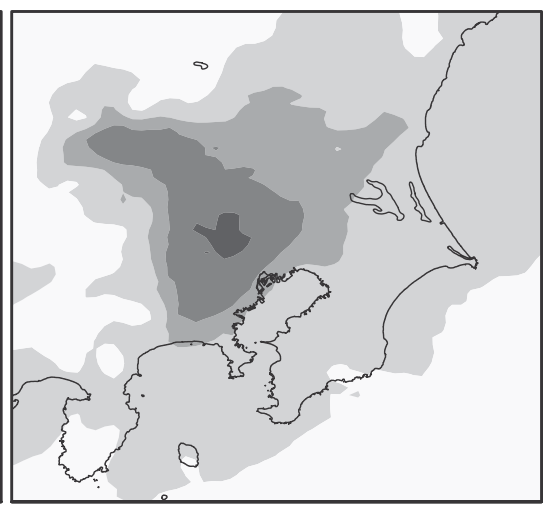

○ (c)

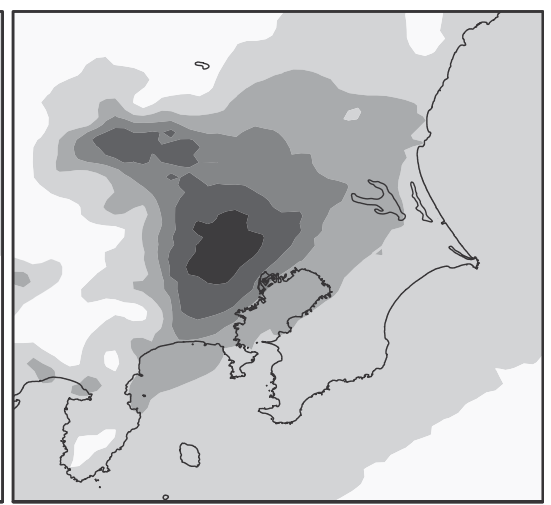

$[\mathrm{hPa}]$

FIG. 11. Urban impacts (anomalies from NU) on the monthly surface pressure during August for (a) CTRL, (b) HB1, and (c) HB2.

integrated divergence of the subgrid-scale horizontal $Q^{\prime}$ flux (horizontal diffusion term). The third term is mainly the evaporation from the land surface, that is, the subgrid-scale vertical $Q^{\prime}$ flux at the surface. The fourth term PR is precipitation. Generally, the horizontal diffusion term is much smaller than the horizontal advection terms, and therefore we merge the first and second terms. This merged term is mostly dominated by the divergence of the horizontal moisture flux. We integrate Eq. (1) over the 1-31 August for each model grid point, average each of the water budget terms over central Tokyo (the black box region in Fig. 7), and then calculate the ensemble mean water budget by averaging over the 32 members ( $8 \mathrm{yr}$ for each of the four boundary conditions).

Figure 13 shows the results of column water budget analysis for the CTRL and NU experiments. In NU, the precipitation amount of $186 \mathrm{~kg} \mathrm{~m}^{-3}$ is almost balanced by the evaporation of $113 \mathrm{~kg} \mathrm{~m}^{-3}$ from the land surface and the convergence of $73 \mathrm{~kg} \mathrm{~m}^{-3}$ from the horizontal moisture flux. For CTRL, the precipitation amount is $197 \mathrm{~kg} \mathrm{~m}^{-3}$, which exceeds NU by $11 \mathrm{~kg} \mathrm{~m}^{-3}$. However, the evaporation of $67 \mathrm{~kg} \mathrm{~m}^{-3}$ is less than NU by $46 \mathrm{~kg} \mathrm{~m}^{-3}$. This decrease is attributed solely to the modification of land cover from grassland to urban. (The analysis domain includes ocean surface, but this surface was unchanged between NU and CTRL.) In contrast, CTRL has a larger convergence of horizontal moisture flux, reaching $130 \mathrm{~kg} \mathrm{~m}^{-3}$, which is $56 \mathrm{~kg} \mathrm{~m}^{-3}$ higher than NU.

To summarize, urbanization increases the amount of precipitation for the following reasons:

1) increases in the sensible heat flux;

2) elevation of the PBL height and average temperature within the boundary layer, which destabilizes the atmosphere and produces anomalous surface low pressure;

3) simultaneous alterations to the sea-breeze circulation pattern and the induction of an anomalous gridscale horizontal moisture flux convergence around central Tokyo;

4) increases in the convergence of the grid-scale horizontal moisture flux, overcoming the reduction of the latent heat flux; and

5) in addition to the mechanism outlined in reasons 3 and 4 , destabilization of the atmosphere itself.

Finally, how does urbanization affect precipitation intensity in Tokyo? With increased urban forcing, precipitation increases in all intensity ranges, but particularly in the category above $35 \mathrm{~mm}(3 \mathrm{~h})^{-1}$ (Fig. 14). However, the climatological approach used here does not readily address the mechanism of precipitation change by intensity range. To do so, the individual rainfall events must be categorized into several types using numerous data points from the simulations, which requires further analysis.

\section{Discussion}

Observations show that summertime localized heavy rainfalls in Tokyo are preceded by a rapid increase in PWV (Kanda et al. 2000; Seko et al. 2007; Kusaka et al. 2009) and the local convergence of easterly and southerly sea breezes (Fujibe et al. 2002; Nakanishi and Hara 2003; Seko et al. 2007). Kusaka et al. (2000) examined the impact of land-use alteration from 1900 to 1985 on the daytime UHI and sea breeze over the Tokyo metropolitan area during summer. The results indicated that the resulting increase in surface sensible 
(a)

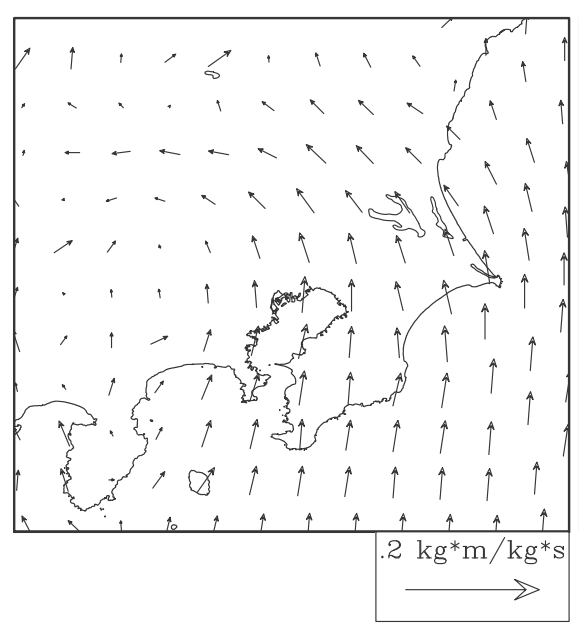

(c) (b)

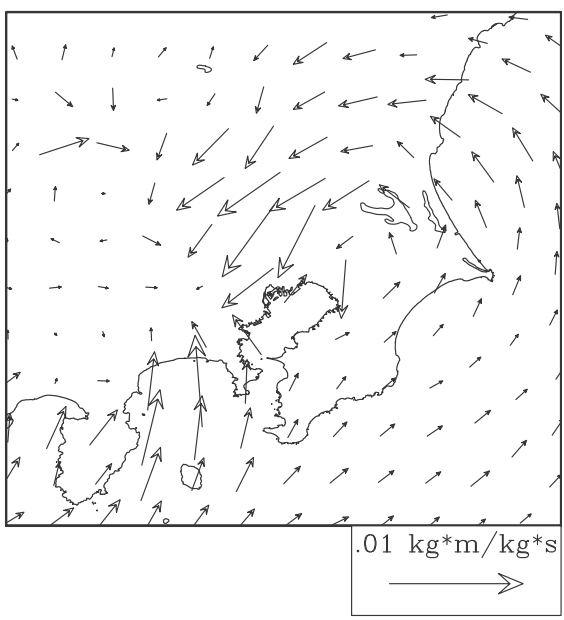

(d)

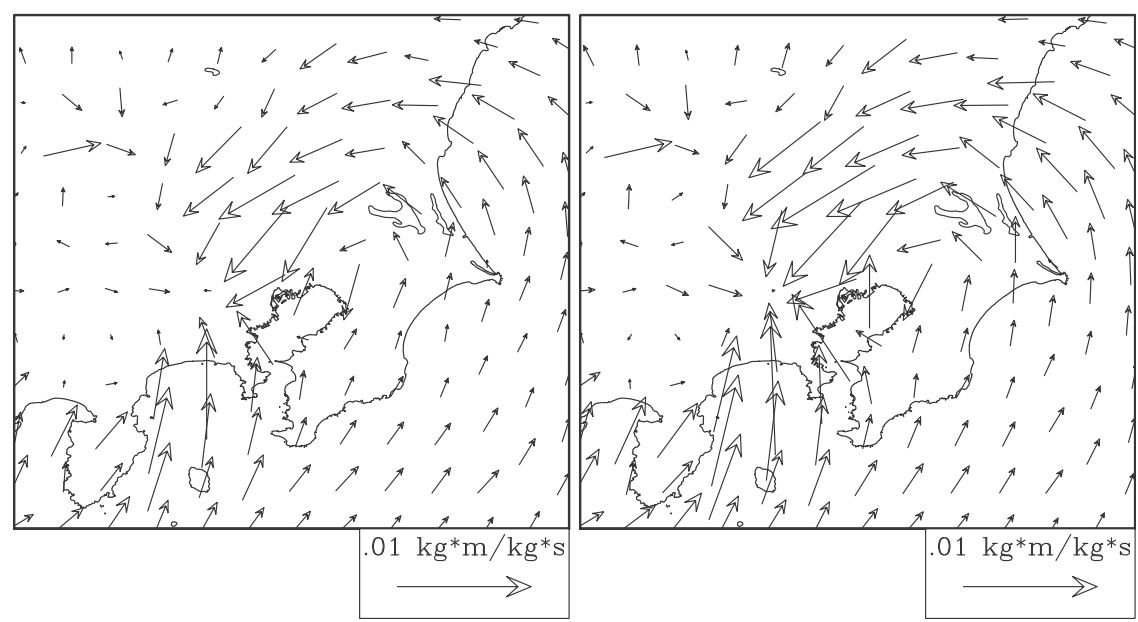

FIG. 12. Spatial distribution of the ensemble mean horizontal moisture flux at $200 \mathrm{~m}$ above the surface during August averaged for 2001-08: (a) NU, (b) difference between CTRL and NU, (c) difference between HB1 and NU, and (d) difference between HB2 and NU.

heat flux has made the sea-breeze front more clearly defined and increased by $2 \mathrm{~h}$ the time required for the sea breeze to reach inland areas. This modification of the sea breeze should decrease the inland moisture transport while increasing the moisture transport to the Tokyo urban area, just as we confirmed in the simulations here. Moreover, when precipitation occurs over the mountains, such a sea-breeze modification would inhibit the convergence of sea breezes and cold outflow from squall lines near the foothills. Results in the current study are in line with the above observational and numerical studies.

There are some mechanisms proposed for the urban impacts of precipitation for Tokyo: mechanical uplift due to high-rise buildings (Shimoju et al. 2009; Takahashi et al. 2011), increased atmospheric instability associated with the urban heat island (Fujibe et al. 2002), and horizontal convergence associated with modifications of the sea breeze, leading to uplift (Fujibe et al. 2002; Shimoju et al. 2010) as well as heat and moisture buildup over the urban area (Inamura et al. 2011; Shimoju et al. 2010; Nakano et al. 2013). Based on moisture budget analysis in the column atmosphere, the present study has shown the importance of the moisture buildup effect. The atmospheric instability effect is also supported by the present study. Note here that the previous studies assessed the above mechanism only qualitatively, whereas the current study provided a quantitative assessment based on physical understanding. 

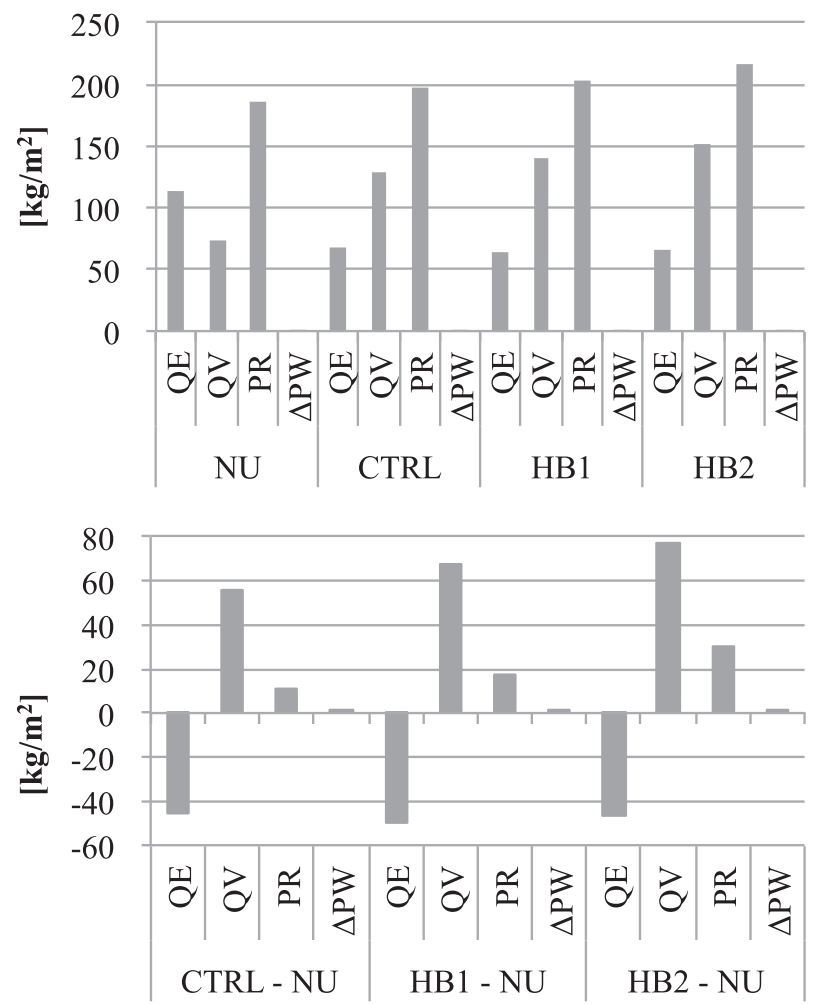

FIG. 13. Calculated water budget terms in the column atmosphere; QE is time-integrated latent heat flux from the surface, QV is time- and vertically integrated horizontal moisture flux, PR is precipitation, and $\Delta \mathrm{PW}$ is change in precipitable water.

There are some important components of urban precipitation that are not considered in the present study. In particular, we did not consider aerosol impact. Urban areas produce large amounts of pollution that increase the number of cloud condensation nuclei. One argument is that higher aerosol concentrations decrease the mean droplet radius, reducing coalescence and thus inhibiting precipitation formation (Rosenfeld 2000; Kaufmann et al. 2007). But a study using a three-dimensional mesoscale model with bulk microphysics (van den Heever and Cotton, 2007) suggested that urban aerosols can enhance convective precipitation. Recently, Han et al. (2012) investigated the impacts of urban aerosols on clouds and precipitation using a two-dimensional mesoscale model with bin microphysics. The results showed that a higher aerosol concentration tends to intensify deep convection but delays the onset of precipitation. A cold-rain-type bin model would be ideal for simulating the aerosol impact on precipitation, but is computationally expensive in a climatological simulation. A further increase of computational capacity would enable climatological simulations with aerosol impacts.

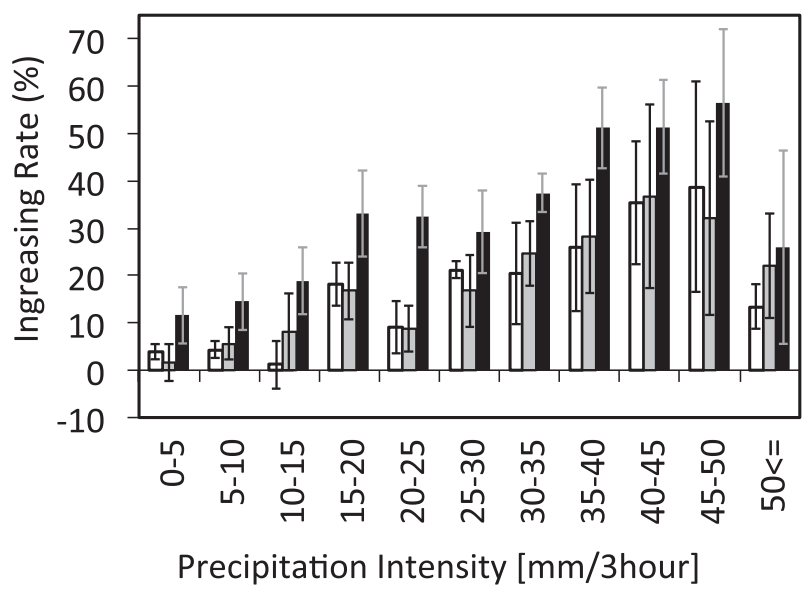

FIG. 14. Urban impact on precipitation intensity per $3 \mathrm{~h}$ during 2001-08 over the urban area. Urban impact is shown as the rate of increase. The bars indicate increasing rate for CTRL (white), HB1 (gray), and HB2 (black). All results are an ensemble mean from the four WRF members. Error bars indicate the spread of the ensemble members.

There are some limitations in the UCM used in this study. First, urban parameters (building height, green fraction, anthropogenic heat release, etc.) for urban and rural areas are set accordingly to distinguish these areas, but their spatial variations within each of the areas are not considered. Second, anthropogenic heat release is configured to follow an observed diurnal variation, but does not have day-to-day variation associated with variable weather conditions. Inclusion of these spatial and temporal variations in urban parameters is left as a future work. Last, using a more sophisticated multilayer UCM would allow for a more realistic representation of the urban processes.

The current study used four different sets of boundary conditions to create ensemble members. To increase the number of ensemble members, multiphysics ensemble experiments can also be as effective as multiboundary forcing ensembles. Assessments of urban impacts on precipitation using multiphysics/boundary condition ensemble simulations are left for future studies.

\section{Summary}

We used an ensemble, regional climatological simulation approach to examine the urban impact on the precipitation climatology of Tokyo. First, we confirmed the reproducibility of the precipitation climatology in Tokyo and its surroundings. Second, results of a CTRL experiment with realistic urban forcing were compared with that of our NU experiment without urban forcing. Third, the results of the CTRL experiment were compared with those of additional experiments with stronger 
(a)

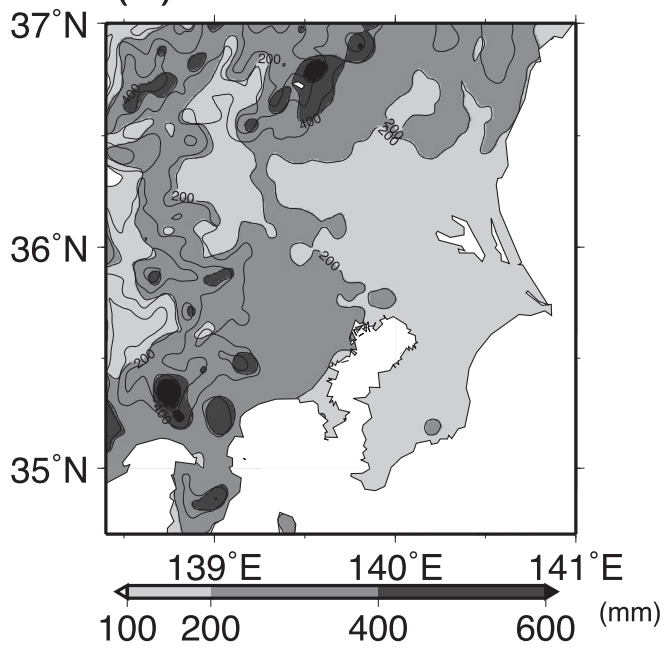

(c)

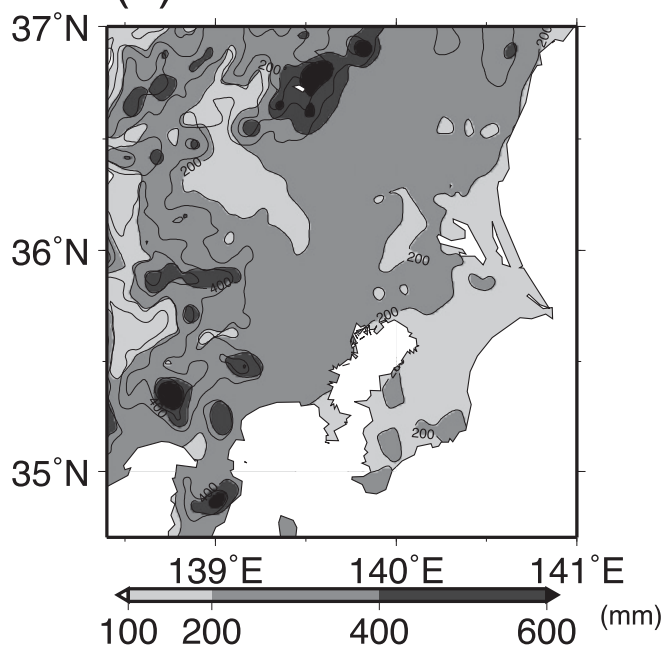

(b)

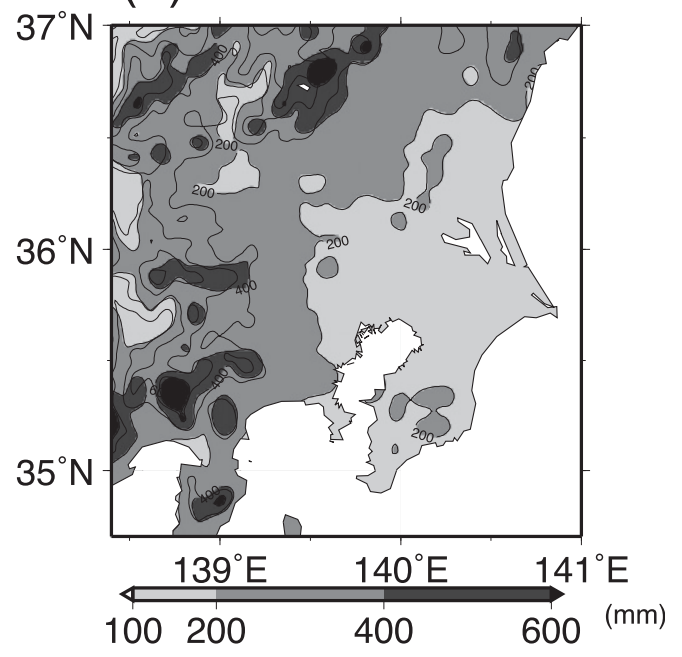

(d)

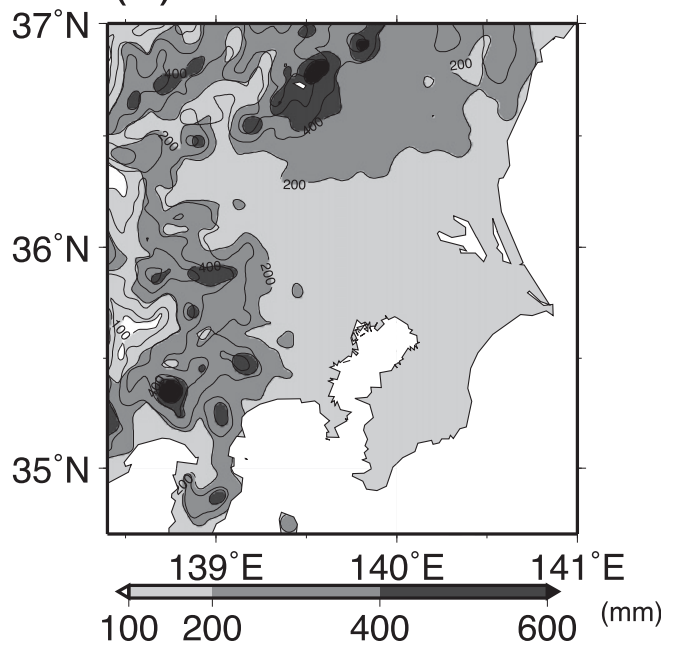

FIG. A1. Simulated spatial distribution of monthly accumulated precipitation in August averaged for 2001-08 with four boundary conditions: (a) FNL, (b) JRA25, (c) MANAL, and (d) RANAL.

urban forcings (HB1 and HB2 experimental cases). Finally, the mechanism of urban influence on the precipitation climatology of Tokyo was investigated by water budget analysis in the atmospheric column over central Tokyo. The results are summarized as follow:

- The model presented successfully reproduced the general features of the observed monthly mean precipitation distribution during the Augusts of 2001-08 with a spatial correlation of 0.78 and a bias of $+24 \%$. The frequent distribution of precipitation intensity per $3 \mathrm{~h}$ was also generally well simulated.

- Current urbanization has increased precipitation $10 \%-$ $15 \%$ in coastal urban areas relative to the situation in which Tokyo is replaced with grassland, and this anomaly is statistically significant at $95 \%$ and $99 \%$ in some regions. Small patches of positive and negative anomalies occurred in the surrounding plain and ocean areas, but there was no statistical significance in most of these patchy anomalies. A negative anomaly occurred near the foothills, and this anomaly is statistically significant at the 95\% and 99\% levels in some areas.

- Strengthened urbanization increased the above effect on precipitation, and this anomaly is statistically significant at the $99 \%$ level.

- Urbanization caused the precipitation in the metropolitan area to increase in all intensity ranges, but most strongly in the heavy precipitation category of over $35 \mathrm{~mm}(3 \mathrm{~h})^{-1}$. 
(a)

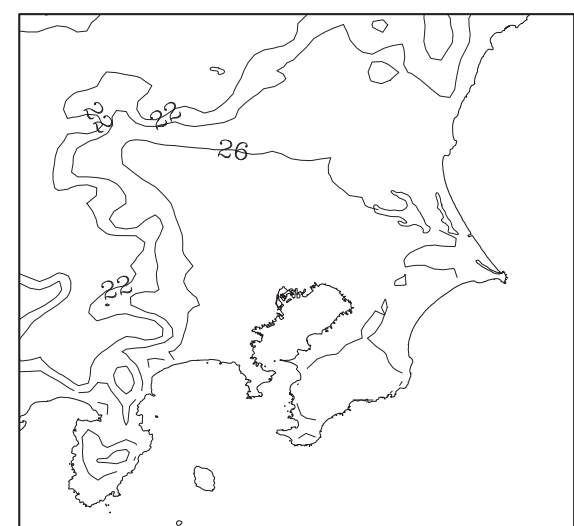

(c)

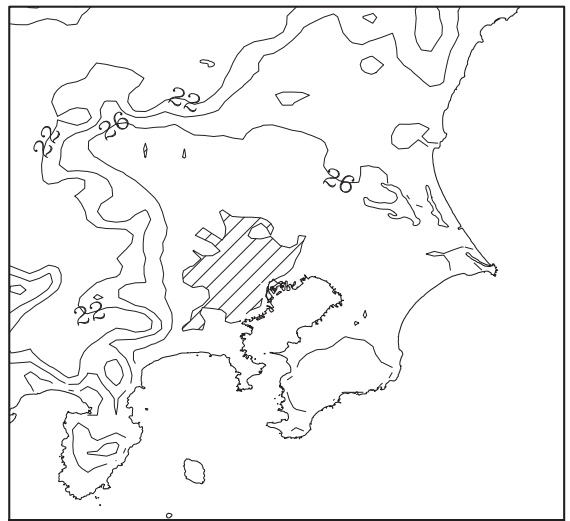

(b)

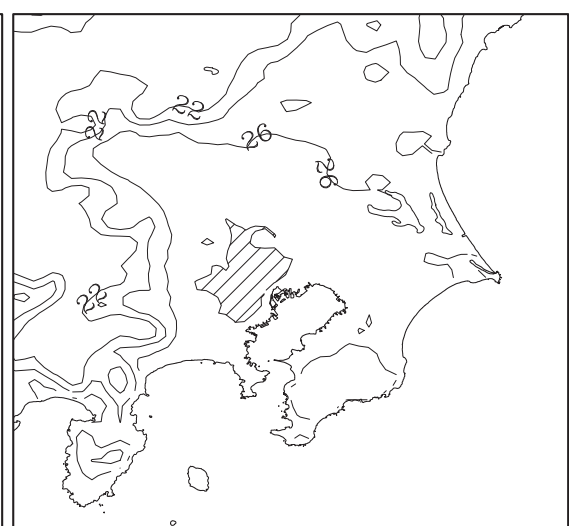

(d)

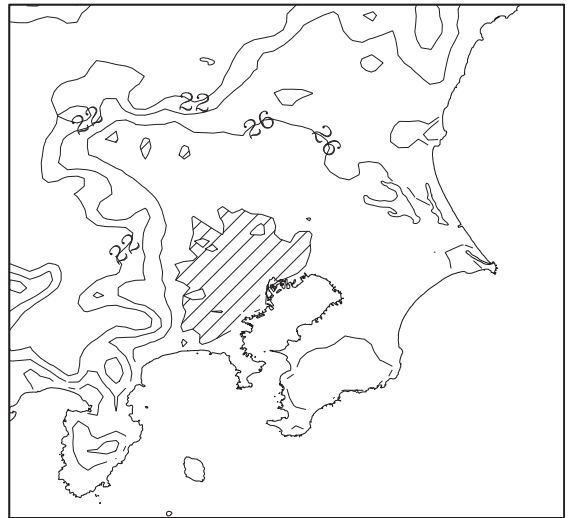

FIG. A2. As in Fig. 9, but for 2-m air temperature. Areas with temperature $>28^{\circ} \mathrm{C}$ are indicated with diagonal lines.

- Urbanization decreased the latent heat flux from the land surface, but increased the sensible heat flux. This increase produced an anomalous surface low pressure, which modified the sea-breeze circulation and the advection of moisture flux to Tokyo. This modification increased the convergence of horizontal moisture flux, resulting in an overall increase in the precipitation around central Tokyo.

Acknowledgments. This work was conducted within the framework of the "Development of Basic Technology for Risk Information on Climate Change" supported by the SOUSEI program of the Ministry of Education, Culture, Sports, Science, and Technology. This work was partially supported by the Research Program on Climate Change Adaptation (RECCA) of the Ministry of Education, Culture, Sports, Science and Technology. Numerical calculations for the present work have been carried out under the "Interdisciplinary Computational Science Program" at the Center for Computational Sciences, University of Tsukuba.

\section{APPENDIX}

\section{Additional Results}

Figure A1 shows August precipitation results for individual ensemble members. Figure A2 gives surface air temperature results for the four experiments.

\section{REFERENCES}

Baik, J.-J., Y.-H. Kim, and H.-Y. Chun, 2001: Dry and moist convection forced by an urban heat island. J. Appl. Meteor., 40, 1462-1475.

Burian, S. J., and M. J. Shephard, 2005: Effect of urbanization on the diurnal rainfall pattern in Houston. Hydrol. Processes, 19, 1089-1103.

Castro, C. L., R. A. Pielke Sr., and G. Leconcini, 2005: Dynamical downscaling: Assessment of value retained and added using the Regional Atmospheric Modeling System (RAMS). J. Geophys. Res., 110, D05108, doi:10.1029/2004JD004721.

Changnon, S. A., 1981: METROMEX: A Review and Summary. Meteor. Monogr., No. 40, Amer. Meteor. Soc., 181 pp.

Chen, F., and J. Dudhia, 2001: Coupling an advanced land surfacehydrology model with the Penn State-NCAR MM5 modeling 
system. Part I: Model description and implementation. Mon. Wea. Rev., 129, 569-585.

— , and Coauthors, 2011: The integrated WRF/urban modelling system: Development, evaluation, and applications to urban environmental problems. Int. J. Climatol., 31, 273-288.

Dixon, P. G., and T. L. Mote, 2003: Patterns and causes of Atlanta's urban heat island-initiated precipitation. J. Appl. Meteor., 42, 1273-1284.

Dudhia, J., 1989: Numerical study of convection observed during the Winter Monsoon Experiment using a mesoscale twodimensional model. J. Atmos. Sci., 46, 3077-3107.

Fujibe, F., K. Sakagami, K. Chubachi, and K. Yamashita, 2002: Surface wind patterns preceding short-time heavy rainfall in Tokyo in the afternoon of midsummer days (in Japanese with English abstract). Tenki, 49, 395-405.

-, H. Togawa, and M. Sakata, 2009: Long-term change and spatial anomaly of warm season afternoon precipitation in Tokyo. SOLA, 5, 17-20.

Gero, A. F., and A. J. Pitman, 2006: The impact of land cover change on a simulated storm event in the Sydney basin. J. Appl. Meteor. Climatol., 45, 283-300.

Guo, X., D. Fu, and J. Wang, 2006: Mesoscale convective precipitation system modified by urbanization in Beijing city. Atmos. Res., 82, 112-126.

Han, J.-Y., J.-J. Baik, and A. P. Khain, 2012: A numerical study of urban aerosol impacts on clouds and precipitation. J. Atmos. Sci., 69, 504-520.

Hong, S.-Y., and H.-L. Pan, 1996: Nonlocal boundary layer vertical diffusion in a medium-range forecast model. Mon. Wea. Rev., 124, 2322-2339.

__ J. Judhia, and S.-H. Chen, 2004: A revised approach to ice microphysical processes for the bulk parameterization of clouds and precipitation. Mon. Wea. Rev., 134, 23182341.

—, Y. Noh, and J. Dudhia, 2006: A new vertical diffusion package with an explicit treatment of entrainment processes. Mon. Wea. Rev., 134, 2318-2341.

Huff, F. A., and S. A. Changnon, 1972: Climatological assessment of urban effects on precipitation at St. Louis. J. Appl. Meteor., 11, 823-842.

Inamura, T., T. Izumi, and H. Matsuyama, 2011: Diagnostic study of the effects of a large city on heavy rainfall as revealed by an ensemble simulation: A case study of central Tokyo, Japan. J. Appl. Meteor. Climatol., 50, 713-728.

Ishizaki, N. N., and Coauthors, 2012: Improved performance of simulated Japanese climate with a multi-model ensemble. J. Meteor. Soc. Japan, 90, 235-254.

Kanda, M., T. Ishida, M. Kashima, and S. Oishi, 2000: Analysis of temporal and spatial change of a convective thunder storm in Tokyo metropolitan using GPS precipitable water: Case study on 23rd August in 1997 (in Japanese with English abstract). Tenki, 47, 7-15.

Kaufmann, R. K., K. C. Seto, A. Schneider, Z. Liu, L. Zhou, and W. Wang, 2007: Climate response to rapid urban growth: Evidence of a human-induced precipitation deficit. J. Climate, 20, 2999-2306.

Kusaka, H., and F. Kimura, 2004a: Coupling single-layer urban canopy model with a simple atmospheric model: Impact on urban heat island simulation for an idealized case. J. Meteor. Soc. Japan, 82, 67-80.

, and $-2004 \mathrm{~b}$ : Thermal effects of urban canyon structure on the nocturnal heat island. J. Appl. Meteor. Climatol., 43, 1899-1910.
H. Hirakuchi, and M. Mizutori, 2000: The effects of land-use alteration on the sea breeze and daytime heat island in the Tokyo metropolitan area. J. Meteor. Soc. Japan, 78, 405420.

_, H. Kondo, Y. Kikegawa, and F. Kimura, 2001: A simple single-layer urban canopy model for atmospheric models: Comparison with multi-layer and slab models. Bound.-Layer Meteor., 101, 329-358.

_ - F. Kimura, K. Nawata, T. Hanyu, and Y. Miya, 2009: The chink in the armor: Questioning the reliability of sensitivity experiments in determining urban effects on precipitation patterns. Proc. Seventh Int. Conf. on Urban Climate, Yokohama, Japan, WMO, B12.2. [Available online at http://www. ide.titech.ac.jp/ icuc7/extended_abstracts/index-web.html.]

_, T. Takata, and Y. Takane, 2010: Reproducibility of regional climate in central Japan using the 4-km resolution WRF model. SOLA, 6, 113-116.

—, F. Chen, M. Tewari, J. Dudhia, D. O. Gill, M. G. Duda, W. Wang, and Y. Miya, 2012a: Numerical simulation of urban heat island effect by the WRF model with 4-km grid increment: An inter-comparison study between the Urban Canopy Model and Slab Model. J. Meteor. Soc. Japan, 90B, 33-45.

_- M. Hara, and Y. Takane, 2012b: Urban climate projection by the WRF model at 3-km horizontal grid increment: Dynamical downscaling and predicting heat stress in the 2070's August for Tokyo, Osaka, and Nagoya metropolises. J. Meteor. Soc. Japan, 90B, 47-63.

Lin, C.-Y., W.-C. Chen, P.-L. Chang, and Y.-F. Sheng, 2011: Impact of the urban heat island effect on precipitation over a complex geographic environment in northern Taiwan. J. Appl. Meteor. Climatol., 50, 339-353.

Matheson, M. A., and Y. Ashie, 2008: The effect of changes of urban surfaces on rainfall phenomenon as determined by a non-hydrostatic mesoscale model. J. Meteor. Soc. Japan, 86, 733-751.

Miao, S., F. Chen, Q. Li, and S. Fan, 2011: Impacts of urban progress and urbanization on summer precipitation: A case study of heavy rainfall in Beijing on 1 August 2006. J. Appl. Meteor. Climatol., 50, 806-825.

Mlawer, E. J., S. J. Taubman, P. D. Brown, M. J. Iacono, and S. A. Clough, 1997: Radiative transfer for inhomogeneous atmospheres: RRTM, a validated correlated- $k$ model for the longwave. J. Geophys. Res., 102 (D14), 16663-16682.

Mote, T., M. C. Lacke, and M. J. Shepherd, 2007: Radar signatures of the urban effect on precipitation distribution: A case study for Atlanta, Georgia. Geophys. Res. Lett., 34, L20710, doi:10.1029/2007GL031903.

Nakanishi, M., and Y. Hara, 2003: Characteristics of local winds associated with the intensification of short-time rainfall in the Tokyo urban area in the afternoon of summer days (in Japanese). Tenki, 50, 91-103.

Nakano, K., M. Nakayoshi, C. G. V. Alvin, M. Kanda, S. Adachi, and H. Kusaka, 2013: Simulation of localized heavy rain considering the latest urban parameterizations (in Japanese with English abstract). J. Japan Soc. Civil Eng., 69B, 355-360.

Niyogi, D., P. Pyle, M. Lei, S. P. Arya, C. M. Kishtawal, M. Shepherd, F. Chen, and B. Wolfe, 2011: Urban modification of thunderstorms: An observational storm climatology and model case study for the Indianapolis urban region. J. Appl. Meteor. Climatol., 50, 1129-1144.

Orville, R. E., and Coauthors, 2001: Enhancement of cloud-toground lightning over Houston, Texas. Geophys. Res. Lett., 28, $2597-2600$ 
Rosenfeld, D., 2000: Suppression of rain and snow by urban and industrial air pollution. Science, 287, 1793-1796.

Rozoff, C. M., W. R. Cotton, and J. O. Adegoke, 2003: Simulation of St. Louis, Missouri, land use impacts on thunderstorms. J. Appl. Meteor., 42, 716-738.

Seko, H., Y. Shoji, and F. Fujibe, 2007: Evolution and airflow of a Kanto thunderstorm on 21 July 1999 (the Nerima heavy rainfall event). J. Meteor. Soc. Japan, 85, 455-477.

Shem, W., and M. Shepherd, 2009: On the impact of urbanization on summertime thunderstorms in Atlanta: Two numerical model case studies. Atmos. Res., 92, 172-189.

Shepherd, J. M., H. Pierce, and A. J. Negri, 2002: Rainfall modification by major urban areas: Observations from spaceborne rain radar on the TRMM satellite. J. Appl. Meteor., 41, 689-701.

Shimoju, R., M. Kakayoshi, and M. Kanda, 2009: The impact of convergence sea breeze driven by urban geometry and terrain on localized heavy rain in Tokyo (in Japanese with English abstract). Ann. J. Hydraul. Eng., 53, 277-282.

-, M. Nakayoshi, and M. Kanda, 2010: Case analyses of localized heavy rain in Kanto considering urban parameters (in Japanese with English abstract). Ann. J. Hydraul. Eng., 54, 349-354.
Skamarock, and Coauthors, 2008: A description of the Advanced Research WRF version 3. NCAR Tech. Note NCAR/TN475+STR, 113 pp.

Takahashi, H., Y. Nakamura, and H. Suzuki, 2011: Frequency distribution of intense rainfall in the wards of Tokyo and its relationship with the spatial structure of building heights (in Japanese with English abstract). J. Geogr., 120, 359-381.

Thielen, J., W. Wobrock, A. Gadian, P. G. Mestayer, and J.-D. Creutin, 2000: The possible influence of urban surfaces on rainfall development: A sensitivity study in $2 \mathrm{D}$ in the mesogammascale. Atmos. Res., 54, 15-39.

van den Heever, S. C., and W. R. Cotton, 2007: Urban aerosol impacts on downwind convective storms. J. Appl. Meteor. Climatol., 46, 828-850.

Westcott, N. E., 1995: Summertime cloud-to-ground lightning activity around major midwestern urban areas. J. Appl. Meteor., 34, 1633-1642.

Zhang, C. L., F. Chen, S. G. Miao, Q. C. Li, X. A. Xia, and C. Y. Xuan, 2009: Impacts of urban expansion and future green planting on summer precipitation in the Beijing metropolitan area. J. Geophys. Res., 114, D02116, doi:10.1029/2008JD010328. 